AUTOR

José Luis Alonso

Santos*

jlalonso@usal.es

* Doctor en Geografía.

Profesor titular de Análisis

Geográfico Regional

del Departamento de

Geografía de la USAL.

\section{Relaciones comerciales entre España y Brasil. Las exportaciones de España en el siglo XXI}

\author{
Relações comerciais entre a Espanha e o Brasil. As exportações da Espanha \\ no século XXI
}

Commercial relations between Spain and Brazil. Exports of Spain in the 21st century

\section{RESUMEN}

El comercio bilateral España-Brasil tenía hasta avanzados los años noventa del siglo XX una intensidad bastante baja en ambas direcciones con saldo positivo, en general, para Brasil. En los últimos años de la centuria, por el contrario, se produce un cambio de ciclo incrementándose notablemente el volumen y naturaleza de los bienes intercambiados. Nos obstante, sólo después de iniciada la crisis económica internacional y en España, desde 2010 el incremento de las exportaciones e importaciones alcanza niveles importantes sólo quebrados en el último bienio debido a la crisis económica y política que aqueja a Brasil.

\section{RESUMO}

Até a década de 1990, o comércio bilateral Espanha-Brasil tinha uma intensidade muito baixa nos dois sentidos, porém com saldo positivo, em geral, para o Brasil. Nos últimos anos da década de 1990, ao contrário, vê-se produzir uma mudança no ciclo, um notável incremento do volume e natureza dos bens intercambiados. Não obstante, somente depois de iniciada a crise econômica internacional e na Espanha, a partir de 2010, o incremento das exportações e importações alcança níveis importantes, somente interrompidos no último biênio, em função da crise econômica e política atual no Brasil.

\section{ABSTRACT}

Bilateral trade Spain-Brazil had advanced to the nineties of the twentieth century a fairly low intensity in both directions with positive balance in general for Brazil. In recent years of the century, however, a cyclical change significantly increasing the volume and nature of the exchanged goods occurs. We, however, started only after the international economic crisis and in Spain, since 2010 the increase in exports and imports reached significant levels only broken in the last two years due to the economic and political crisis afflicting Brazil. 


\section{Antecedentes y estado del tema}

Las relaciones comerciales son uno de los exponentes más relevantes de las relaciones entre los países pues los intercambios económicos funcionan como factor importante de estímulo a las políticas de desarrollo económico y social. En la segunda mitad del siglo veinte los países de la órbita capitalista, desarrollados o no, se involucran en intercambios económicos internacionales que requieren inducir en su actividad económica prácticas y procesos de producción orientados a generar ventajas competitivas para sus bienes en los mercados internacionales siempre al amparo de las garantías y reglamentación del General Agreement on Tariffs and Trade (GATT) y sus Rondas. En ese contexto de creciente internacionalización de las economías nacionales, los intercambios comerciales entre Brasil y España en los lustros finales del siglo XX aún presentaban niveles modestos, expresión de que para ninguno de los dos países el comercio bilateral es muy importante.

En una economía bastante cerrada a los intercambios comerciales con el exterior como era la brasileña (Audera, 2003; Da Motta, 2003), la introducción de políticas de liberalización económica a partir de 1991-1993 con el Plan Abertura primero y el éxito del Plan Real a partir de 1994 después, abren para el país una nueva fase de creciente internacionalización con notable incremento de los intercambios comerciales (Arahuetes y Hirituka, 2007; Arahuetes et al. 2010; Ayllón 2007; Da Motta, 2003; Utrera, 2003). Como reflejo de esos cambios, frente al carácter poco significativo (Arahuetes et al, 2010) o insignificante (García, 2013), de los intercambios comerciales previos, en el trienio final de la centuria se han incrementado de forma notable las inversiones de España en Brasil, pero también los flujos comerciales entre ambos países.

En esas fechas, las grandes expectativas que el capital español ve en el mercado de Brasil inducen a considerarlo socio estratégico tanto en el campo de la IED (Inversión Exterior Directa) como en el comercio de bienes y servicios. Y en efecto, Brasil junto a México constituyen los dos grandes mercados en América Latina-Caribe para la economía española. Ambos mercados en conjunto superan ampliamente el 50\% de la IED de España en la región y apenas unos puntos les faltan en comercio (46,1\% media de 2014-2015). Pero mientras la IED de Brasil supera ampliamente a México: 59.327,6 millones de euros por 35.116,8 millones de euros de 1993-2015 (Alonso, Mendes \& Guarnieri, 2017, p. 181) en comercio, excepción hecha de 2013, México supera a Brasil en varios puntos. En suma, como se constata en el análisis de los valores de los intercambios durante los años del presente siglo, a pesar de los acuerdos y encuentros bilaterales de carácter comercial realizados, el valor de los intercambios comerciales entre Brasil y España permanece por debajo de los potenciales niveles que el tamaño y complementariedad de ambas economías permitirían alcanzar.

Como apuntara el profesor Juan Velarde, citando a The Economist, en los años finales de la anterior centuria en Iberoamérica "muchos gobiernos proclamarán su compromiso con el libre comercio, mientras, de manera discreta, les aprietan las clavijas a las importaciones" (Velarde, 2003, p. 52) ya que aún mantienen un desarme arancelario limitado a causa del arraigado nacionalismo económico. La creación en 1998 de la Agencia de Promoción de las Exportaciones (APEX-Brasil) será una de las herramientas orientadas a la promoción de los productos brasileños en el exterior (Quirós, 2003, p. 42). No obstante, en la medida en que la cultura proteccionista permanece en los intersticios de la administración hacia el exterior, infiere un grado de apertura comercial de Brasil netamente menor al español, plenamente abierto al mercado común y la globalización.

En este trabajo, una vez contextualizado, se parte en un segundo apartado de una breve presentación de la naturaleza y dinámica de la economía de ambos países en el periodo de estudio de modo que se identifican las fases o momentos de mayor y menor vitalidad de cada economía (PIB) a la vez que se relaciona con el ritmo de las importaciones del mundo y desde España para la 
economía de Brasil, lo que permite ponderar en qué grado las importaciones del mundo y de España evolucionaron de forma similar o diferente. El tercer apartado se centra en el estudio de los cambios y condiciones de las relaciones económicas BrasilEspaña fraguadas en los años noventa de la centuria pasada elaborada en base a los trabajos específicos citados y relacionados al final del texto para, en el cuarto apartado de 2000 a 2015, el central y más amplio del texto, realizar el seguimiento de las exportaciones españolas analizando la base de datos ESTACOM elaborada por ICEX (Instituto Español de Comercio Exterior) con la información de la Secretaría General de Comercio Exterior. La fuente facilita el seguimiento de las exportaciones e importaciones por años entre España y Brasil.

Para el estudio de las exportaciones, objetivo del trabajo, se ha analizado para cada año la naturaleza y el valor de los bienes transados ordenados por sector y rama de actividad en base a la clasificación de la CNAE-2009. Ello permite identificar cuáles son los bienes exportados por España en mayor intensidad y captar los posibles cambios que a lo largo de los años 2000-2015 pudieran producirse en su naturaleza. Para mejor conocer y analizar la identidad y composición de las exportaciones se ha contrastado en el tiempo tres bienios: el inicial de 2000-2001, el de 2007-2008 y el final 20142015. La información que facilita ESTACOM permite también identificar en el tiempo dos fases o etapas por el monto o valor de los bienes exportados. La primera cubre los años 2000 a 2007 anteriores a la crisis económica en España y marcada por el estancamiento o debilidad de los intercambios a partir de 2001, mientras la segunda etapa 20082015, de grave crisis económica del mercado interior presenta, en cambio, notable incremento del comercio bilateral con Brasil al menos hasta 2013. Las conclusiones e ideas finales conforman el quinto punto del texto y cierran los contenidos del trabajo.

\section{El contexto macroeconómico de España y Brasil de los años 1990 al presente. Divergencias presentes}

Aunque el periodo de estudio es bastante reducido, en él se pueden observar cambios muy importantes tanto en la economía de Brasil como en la de España además de entre ambas economías. El inicio de la centuria actual presenta dos economías con claras diferencias en su composición por sector de actividad resultado de procesos históricos de desarrollo más evolucionado el español que el de Brasil. En el año 2000, el sector primario en España reducía su aportación al PIB nacional al 4,4\% con una masa laboral de apenas el 6,1\%, sin embargo, los indicadores en 2002 para este mismo sector de actividad en la economía de Brasil, se elevan al 8,8\% en PIB y el 18,5\% en ocupación laboral. En paralelo, el complejo sector de los servicios terciarios contabiliza el $66,1 \%$ de la renta final de España y apenas alcanza el 52,8\% en Brasil (CIDOB, 2004, pp. 563-565).

Pero tal vez, lo más llamativo de los cambios operados en estos años sea que en el umbral del presente siglo, medidas ambas economías en valor de su PIB, la española (648.250,0 millones/€) era mayor que la de Brasil (508.931,3 millones/US\$). Sin embargo, en la actualidad -2015- la de Brasil es muy superior (2.32 billones/US\$) frente a 1.07 billones/€ la de España. Es decir, el PIB de Brasil subió al 455,7\% en el periodo mientras el de España lo hacía al $167 \%$. Por lo demás, la Tabla 1 muestra el comportamiento anual de ambas economías, las similitudes y diferencias de la evolución de su PIB así como permite contrastar, de modo especial para Brasil, su trayectoria con la de sus importaciones tanto mundiales como procedentes de España en particular. (Tabla 1).

De 2000 a 2015, las importaciones totales de Brasil escalan hasta el 429,4\% en 2013 (año 2000: 100) si bien la posterior crisis económica las contrae al 309\% en 2015 y a 244,3\% en 2016 (Tabla 2). En paralelo, las importaciones procedentes de España se incrementan a menor ritmo que las totales alcanzando su máximo valor en 2013 (289,8\%) y estarán sometidas, al igual que las del mundo, a fuertes oscilaciones de un año para otro, aunque no siempre en fechas coincidentes. En última instancia, hay que señalar para la economía de Brasil que el porcentaje de incremento de las importaciones será sistemáticamente inferior al del PIB. Lo contrario sucede en la economía de España donde las exportaciones totales (205\% en 2016) han crecido 
a mayor ritmo que el PIB así como únicamente sufren pérdida de valor en 2009 y también ofrecen gran regularidad en su progresión, circunstancia que difiere claramente de la volatilidad que aqueja a las importaciones brasileñas, circunstancia que permite observar la propia Tabla 2 que acompaña. (Tabla 2).

Tabla

\begin{tabular}{|c|c|c|c|}
\hline \multicolumn{4}{|c|}{$\begin{array}{l}\text { Indicadores económicos básicos. } \\
\text { Evolución del PIB (\%) }\end{array}$} \\
\hline Fecha & Brasil & España & $\begin{array}{c}\text { A. } \\
\text { Latina }\end{array}$ \\
\hline $1996-2000$ & 2,1 & 4,1 & 3,1 \\
\hline 2000 & 4,4 & 5,3 & 3,9 \\
\hline 2001 & 1,3 & 4,0 & 0,4 \\
\hline 2002 & 1,9 & 2,9 & $-0,8$ \\
\hline 2003 & 0,5 & 3,2 & 2,0 \\
\hline 2004 & 5,7 & 3,2 & 5,8 \\
\hline 2005 & 3,2 & 3,7 & 4,6 \\
\hline 2006 & 3,7 & 4,2 & 5,6 \\
\hline 2007 & 6,1 & 3,8 & 5,8 \\
\hline 2008 & 5,1 & 1,1 & 4,2 \\
\hline 2009 & $-0,2$ & $-3,6$ & $-1,9$ \\
\hline 2010 & 7,5 & 0,1 & 5,9 \\
\hline 2011 & 2,7 & $-0,1$ & 4,3 \\
\hline 2012 & 1,8 & $-2,9$ & 2,9 \\
\hline 2013 & 2,7 & $-1,7$ & 2,8 \\
\hline 2014 & 0,1 & 1,4 & 1,2 \\
\hline 2015 & $-3,9$ & 3,2 & $-0,4$ \\
\hline 2016 & $-3,6$ & 3,2 & $-1,4$ \\
\hline
\end{tabular}

Fuente: CEPAL. Anuario Estadístico varios años; BM e INE para España.

En un nivel de análisis más concreto, la dinámica de ambas economías presenta diferencias relevantes a considerar:

a) En el quinquenio 1996-2000 mientras España disfruta de un incremento medio anual del PIB del $4,1 \%$, Brasil, con serios problemas estructurales e inmerso en reformas económicas de calado con el gobierno de Fernando E. Cardoso, apenas alcanza un crecimiento medio anual del 2,1\% (con tasa negativa del 1,9\% en 1998) así como experimenta pérdida de competitividad en el comercio internacional.
A abertura comercial, juntamente com a sobrevalorização cambial, favoreceu o crescimento das importações num ritmo acelerado ao longo da década de 90. Entre 1994-1999, as importações cresceram $48 \%$, superiores aos $33 \%$ das importações mundiais; enquanto as exportações brasileiras foram $7,9 \%$ contra $32 \%$ de crescimento das exportações mundiais (Espindola, 2014, p. 15),

o también "O saldo da balança comercial brasileira, que apresentava um superávit de US\$10,4 bilhões em 1994, entra em trajetória declinante com déficit de US\$ 3,3 bilhões em 1995, e US\$ 6,6 bilhões em 1998" (Espíndola y Marthins 2017, p. 165).

b) En el periodo 2001-2008 la economía de Brasil presenta dos fases bien diferentes por su dinamismo. Los años 2001 a 2003 serán de muy débil crecimiento económico (el PIB apenas alcanza la media de 1,2\%), en gran medida, lastrado por el efecto de arrastre de la crisis económica que recorre la región (PIB medio -0,8\% en 2002 según CEPAL). En un terreno distinto, el político, se producía la alternancia en el poder con la llegada al gobierno del Partido de los Trabajadores (PT) en 2002. En esos mismos años, la bonanza económica que iniciara la economía de España en la legislatura anterior -1996/2000- se mantiene con el segundo gobierno Aznar -2000-2004- con incremento medio del PIB del 3,4\% de 2001 a 2003. Tasa de incremento anual del PIB que se prolonga, incrementada incluso, hasta el año 2007 en el primer gobierno socialista de Rodríguez Zapatero -2004-2008.

Los años del trienio inicial de la centuria también presentan fuertes divergencias del comercio exterior global y bilateral de ambas economías. Brasil experimenta una acusada contracción de importaciones de 2001 a 2003 con mínimos en 2002 de 47.200 millones/US\$, apenas el 84,6\% del valor del año 2000 y un descenso del 15,1\% sobre el año precedente. Sólo en 2004 el valor de lo importado supera en el 12,5\% al año 2000. Mayor degradación se anotan las importaciones procedentes de España que en 2003 apenas ascienden al 69,9\% del valor de 2000 y registran tasas de regresión respecto del año precedente de menos $24,8 \%$ en 2002 y menos $14,2 \%$ en 2003. Son niveles de contracción claramente 
Tabla 2

\begin{tabular}{|c|c|c|c|c|c|c|}
\hline \multicolumn{7}{|c|}{ Brasil. Evolución de las importaciones del mundo y de España (2000-2015). } \\
\hline \multicolumn{4}{|c|}{ Importaciones del mundo } & \multicolumn{3}{|c|}{ Importaciones desde España } \\
\hline Fecha & Millones/US\$ & 2000: 100 & Variación anual & Millones/€ & 2000: 100 & Variación anual \\
\hline 2000 & 55.800 & 100,0 & & 1.257 & 100,0 & \\
\hline 2001 & 55.600 & 99,6 & $-0,36$ & 1.363 & 108,4 & 8,20 \\
\hline 2002 & 47.200 & 84,6 & $-15,11$ & 1.024 & 81,5 & $-24,80$ \\
\hline 2003 & 48.300 & 86,6 & 2,33 & 879 & 69,9 & $-14,20$ \\
\hline 2004 & 62.800 & 112,5 & 30,02 & 1.088 & 86,6 & 23,90 \\
\hline 2005 & 73.600 & 131,9 & 17,19 & 1.019 & 81,1 & $-6,40$ \\
\hline 2006 & 91.300 & 163,6 & 24,04 & 1.123 & 89,4 & 10,23 \\
\hline 2007 & 120.900 & 216,7 & 32,42 & 1.302 & 103,6 & 15,91 \\
\hline 2008 & 172.900 & 309,9 & 43,01 & 1.641 & 130,6 & 26,05 \\
\hline 2009 & 127.700 & 228,8 & $-26,15$ & 1.345 & 107,1 & $-18,02$ \\
\hline 2010 & 181.700 & 325,6 & 42,28 & 2.202 & 175,2 & 63,69 \\
\hline 2011 & 226.200 & 405,4 & 32,06 & 2.595 & 206,5 & 17,84 \\
\hline 2012 & 223.500 & 400,5 & $-1,20$ & 2.808 & 223,4 & 8,18 \\
\hline 2013 & 239.600 & 429,4 & 7,20 & 3.642 & 289,8 & 29,73 \\
\hline 2014 & 229.100 & 410,6 & $-4,39$ & 3.199 & 254,6 & $-12,17$ \\
\hline 2015 & 172.400 & 309,0 & $-24,75$ & 2.729 & 217,1 & $-14,31$ \\
\hline 2016 & 136.300 & 244,3 & $-20,94$ & 2.245 & 178,7 & $-17,71$ \\
\hline
\end{tabular}

Fuente: BRASIL. Espíndola \& Marthins para 2000-2010.

CEPAL. Informe Estadístico Economía Brasileña para 2011-2014 y Panorama de la inserción internacional de A. Latina-Caribe para 2015-2016.

España: ICEX. ESTACOM.

superiores a los que registran las importaciones de Latinoamérica procedentes de España en esos años (menos 7,4\% en 2002 y menos 4,8\% en 2003). En franca divergencia con el comportamiento de las exportaciones a Brasil y Latinoamérica en esos años, las exportaciones de España crecerán regularmente a tasas que van del $2,7 \%$ en 2002 al $6,4 \%$ en 2004 , de modo que en 2005 su valor se ha incrementado en el $24,8 \%$ respecto de 2000 .

Al fin, desde 2004, el gobierno Lula da Silva abría una etapa de crecimiento económico sostenido con tasas del PIB siempre superior a 3,2\% (2005) y media del quinquenio $2006-2010$ del $4,4 \%$ a pesar del año negro (2009 con saldo negativo de -0,2\%) de la crisis financiera internacional desatada con la quiebra de la firma financiera Lehman Brothers en septiembre de 2008. La divergencia en el crecimiento de ambas economías se hará patente a partir de 2007 en que se vislumbra el final del ciclo expansivo de la economía española. No sólo la caída del PIB en más del 3,6\% en 2009 revela el diferente impacto de la crisis financiera en una y otra economía sino que 2008 con crecimiento apenas del 1,1\% anuncia la grave crisis económica, de empleo y de deuda, que sufrirá el país en los años siguientes.

Excepción hecha de 2009 (caída del 26,1\% del valor de sus importaciones sobre el año anterior) de 2005 a 2011 las importaciones de Brasil crecen a tasas anuales elevadas (entre el $24 \%$ en 2006 y el $43 \%$ en 2008) trayectoria que siguen también las importaciones desde España si bien sus tasas de incremento son más moderadas. Junto al dinamismo del mercado interior, señalan Espíndola y Marthins

Com a valorização do Real pós 2005, as importações passaram a crescer em índices percentuais maiores que as exportações, e, como resultado, os superávits comerciais 
começaram a diminuir gradativamente, alcançando a casa dos US\$ 20 bilhões em 2010 (Espíndola y Marthins 2017, p. 167).

c) De 2010 al presente, España estará determinada por la intensidad de la crisis económica, financiera e inmobiliaria. La desorientación de cómo abordarla así como el corsé presupuestario impuesto por Bruselas y la corrupción desbocada, condicionan la capacidad de gestión política. Precisamente en el terreno político se asiste al hundimiento del segundo mandato socialista y retorna (elecciones anticipadas en 2010) al poder el Partido Popular. Se suceden tasas anuales de PIB negativas en 2011, 2012 y 2013 para sólo retornar en 2015 a un sólido crecimiento. También para Brasil desde 2011 (tercer gobierno del PT con Dilma Rousseff) la debilidad de la actividad económica se acrecienta hasta desembocar en una crisis de crecimiento desde 2014 con fuertes retrocesos del PIB (contracción del 3,9\% en 2015 y del 3,6\% en 2016) que lo sitúan como uno de los enfermos económicos más graves de una región del mundo también en crisis en esos años.

Se podría decir que en los años recientes el comportamiento de las economías de Brasil y España comparten problemas muy graves pero difieren en el ritmo de los mismos. España ha transitado por una aguda crisis de modelo económico mientras Brasil cierra un ciclo expansivo sin modelo de política económica alternativa en el horizonte.

Frente a esas aparentes similitudes, la divergencia entre ambas economías son notables en el comportamiento de su comercio exterior. Las importaciones totales de Brasil que en 2011 han crecido el $32 \%$ respecto a 2010 , en los años siguientes registran tasas negativas (menos en 2013) en especial fuertes en 2015-2016 (-24,7 y $-20,9 \%)$ como reflejo automático de la crisis económica y política que asola el país. En cambio, las importaciones procedentes de España, mantienen niveles de incremento superiores a las totales hasta 2013 así como sus tasas de regresión son más suaves que las totales en los últimos años. La divergencia es rotunda con la economía española. Desde 2010, España tendrá en la vitalidad de las exportaciones uno de los resortes básicos de alivio de la atonía económica persistente. No sólo las empresas que exportan incrementan volumen y valor de lo exportado, sino que también se da el incremento año tras año del número de empresas que venden al exterior de manera regular, fenómeno desconocido en fechas anteriores. $Y$ aunque hacia Brasil y, en general, Latinoamérica, experimentan regresión desde 2014, mantienen saldo positivo año tras año aunque desde 2013 la tasa de crecimiento es baja (entre 2-4\%), lejos del entorno del 16\% que registran en 2010-2011.

\section{Los intercambios comerciales en los años noventa. Liberalización y estrategias de potenciación del comercio}

Sobre la naturaleza y cuantía del comercio bilateral señalan distintos analistas que en los primeros años noventa de la pasada centuria, el valor de los bienes que España vendía a Brasil sitúan a éste en una posición secundaria entre los clientes y, a la vez, España ocupa una posición incluso menos relevante para los bienes exportados por Brasil (Arahuetes \& Hirituka, 2007; Arahuetes et als., 2010; Audera, 2003; Furlán, 2003; Utrera, 2003). Los intercambios se intensifican con la entrada en vigor del Plan Real en 1995. En el bienio 1995-1996, Brasil compraba en España por valor de 1.387 millones de euros equivalentes al 0,93\% del total mundial y el $17,71 \%$ de las exportaciones a América Latina, región que con 7.830 millones de euros absorbía el $5,28 \%$ de las exportaciones españolas. Si bien en el bienio el peso del comercio de exportación de España con Brasil en el conjunto de América Latina es ya destacado y únicamente Argentina presenta valores superiores, ello acontece en el marco de gran debilidad de las ventas comerciales de España en la región.

El bajo perfil del comercio de España con los países de la región se prolonga por la centuria actual e incluso presenta deterioro en los bienios $2003 / 2004$ y 2008/2009 con niveles inferiores al $5 \%$ del total de las exportaciones sin que se observen mayores esfuerzos por parte de España para incrementar la participación de los países de América Latina en su comercio exterior hasta bien 
avanzada la crisis económica que, plasmada en una famélica demanda interna desde 2009, obliga a las empresas a abrir mercados en el exterior de modo que de 2012 a 2015 las exportaciones hacia América Latina retornan a niveles superiores al $6 \%$ (6,47\% en 2013) como sucedía en 2000.

Respecto a los años precedentes, en los años finales de la década de los 90, la situación comercial bilateral ha mejorado de forma sustancial (Arahuetes \& Hirituka, 2007; Ayllón, 2007; Furlán, 2003; Audera, 2003) de modo que en 1998 y hasta 2001 el valor de las exportaciones de España a Brasil más que se doblan respecto al valor de 1996 y años anteriores. En efecto, el comercio bilateral del quinquenio 1995-1999 que arroja saldo final negativo para España de 202 millones de euros, refleja en su desglose por años el cambio (Tabla 3) tanto del valor del comercio como la intensidad de exportaciones e importaciones ya que en el bienio 1995-1996 con débil vigor de los intercambios, el saldo final era muy desequilibrado a favor de Brasil mientras que el incremento de los intercambios en los tres años siguientes arrojan saldo a favor de España con máximo en 1998 en que alcanza cobertura en los intercambios del 105\% (Ayllón, 2007, p. 204). Bien puede considerarse que detrás de la creciente penetración en el mercado local de la imagen país de España está la sólida acción del Instituto Español de Comercio Exterior (ICEX) con la celebración en 1996 de la Expotécnia en São Paulo y la apertura de oficinas económicas y comerciales en Brasilia, Río de Janeiro y São Paulo (Reyero, 2003, p. 36). Superávit a favor de España que debe valorarse como circunstancial ya que no volverá a repetirse hasta el año 2013. Las exportaciones de España a Brasil en el quinquenio equivalen a un débil $0,95 \%$ del total mundial pero ascienden al 25,46\% de las recibidas por América Latina.
Al filo del cambio de siglo, durante el bienio 1998/1999, Brasil se convierte excepcionalmente en el principal socio comercial de España en América Latina-Caribe al superar sus importaciones en valor tanto a Argentina, tradicional socio hegemónico en años anteriores como a México, país que desde el año 2000 ocupará ininterrumpidamente la primera posición como socio comercial de España en la región con la excepción del año 2013, fecha en que las exportaciones a Brasil suben al $23,67 \%$ de las totales a la región frente al $20,97 \%$ que alcanzan las de México.

En 2000 el valor en euros de las compras de Brasil en España (1.256,8 millones/€) ascendían al 1,01\% de las exportaciones al mundo y al $16,65 \%$ respecto de las ventas a América Latina. En los términos siguientes, Audera sintetiza la naturaleza del cambio operado en la segunda mitad de los años 90: "mientras que en 1993 las exportaciones españolas a Brasil fueron de apenas 241,6 millones de dólares, desde los últimos años de la década de los noventa se alcanzó un volumen de exportación española de 1.200 millones de dólares" (Audera, 2003, p. 58). En esos años la composición de las exportaciones por sector de actividad también experimenta cambios que han documentado Arahuetes y Hirituka, "en 1995 la estructura sectorial de las exportaciones de España a Brasil mostraba una alta concentración (82\%) en tres sectores: automóvil (35\%), bienes de equipo $(29,6 \%)$ y semimanufacturas $(17,5 \%)$ ". Sin embargo, prosiguen los autores, en 2000 los tres sectores mantienen la fuerte concentración pero el sector del automóvil ha caído al 8,5\%, los bienes de equipo se elevan al $52,8 \%$ y las semimanufacturas alcanzan el 20,5\%" (Arahuetes \& Hirituka, 2007, pp. 73-74).

Tabla 3

\begin{tabular}{|l|c|c|c|c|c|c|}
\hline \multicolumn{7}{|c|}{ Saldo comercial España-Brasil (1995-1999; millones de euros). } \\
\hline & 1995 & 1996 & 1997 & 1998 & 1999 & $1995 / 1999$ \\
\hline Exportaciones & 652 & 735 & 1.140 & 1.228 & 1.294 & 5.049 \\
\hline Importaciones & 849 & 886 & 1.106 & 1.159 & 1.251 & 5.251 \\
\hline Saldo & -197 & -151 & 34 & 69 & 43 & -202 \\
\hline
\end{tabular}

Fuente: Elaborado con datos Arahuetes \& Hirituka (2007), pp. 57-65. 


\section{Las exportaciones de España a Brasil en el siglo XXI}

\subsection{Grado de las exportaciones 2000-2015}

Las relaciones comerciales bilaterales del periodo presentan intensidad diferente entre exportaciones e importaciones si bien unas y otras han más que doblado su valor (Gráfico 1). La dinámica de las exportaciones de España viene determinada, a partir de 2001, por la recesión hasta 2007, año en que su valor asciende al 103,59\% del alcanzado en el año 2000. En cambio, las fechas siguientes se caracterizan por un notable incremento con umbral mínimo en el fatídico 2009 y máximo en 2013 cuando el valor de lo exportado, 3.642 millones de euros, alcanza el $289,81 \%$ respecto a 2000 . No obstante, el bienio 2014-2015 acusa claramente los efectos de la crisis del mercado brasileño -inflación del 6,3\% en 2014 (ICE, 2015, p. 63) y el 10,6 en 2015 según el Instituto Brasileño de Geografía y Estadística (IBGE), incremento del desempleo y la informalidad- de modo que las exportaciones de 2015 son inferiores en un $14,6 \%$ a las de 2014 que, a su vez, habían sido el $12,2 \%$ más reducidas que las del año anterior (ICEX, 2016, p. 6).

Las exportaciones de España a Brasil y a algunos otros mercados (Argentina) de América LatinaCaribe, presentan de 2001 a 2008 dos fases diferentes, marcada la inicial hasta 2004 por la recesión y atonía económica con pérdida significativa de valor de los bienes procedentes de España (tasas negativas interanuales para Brasil del
$-24,8 \%$ en 2002 y -14,2\% en 2003 y más suaves para América Latina: $-7,4 \%$ en 2002 y $-4,8 \%$ en 2003 ) de modo que en 2004 apenas equivalen al 86,6\% en Brasil y al 93,9\% en América Latina respecto de su valor en el año 2000 (1.256,8 mills/€ Brasil y 7.547,5 mills/€ América Latina). Los años siguientes abren una segunda fase marcada por la sucesión de tasas de crecimiento económico relativamente altas tanto en Brasil como en la región, aunque su traslado al crecimiento de las importaciones españolas sólo se plasma en la región en un valor superior al del año 2000 a partir de 2005 (valor del $107,1 \%)$ si bien en Brasil esa recuperación no llega hasta 2007 (103,6\%). El valor de las exportaciones de España hacia América Latina-Caribe en 2008 respecto a 2000 eran el $24,3 \%$ superiores y hacia Brasil el incremento fue del 30,6\%.

En esos mismos años 2001-2008, las exportaciones totales de España incrementan año tras año su valor de modo que en 2004 son un 18,3\% superiores a 2000 y escalan al $52,4 \%$ en 2008 . En suma, un comportamiento del comercio exterior de España bastante más dinámico hacia el resto del mundo que hacia Brasil y América Latina-Caribe. De los datos se deduce que las razones principales del menor crecimiento del comercio exterior de España hacia Brasil e lberoamérica han de buscarse en la dinámica interna de la economía española y las estrategias de internacionalización seguidas en esos años que son, recordemos, de contínuo y fuerte crecimiento del mercado interior.

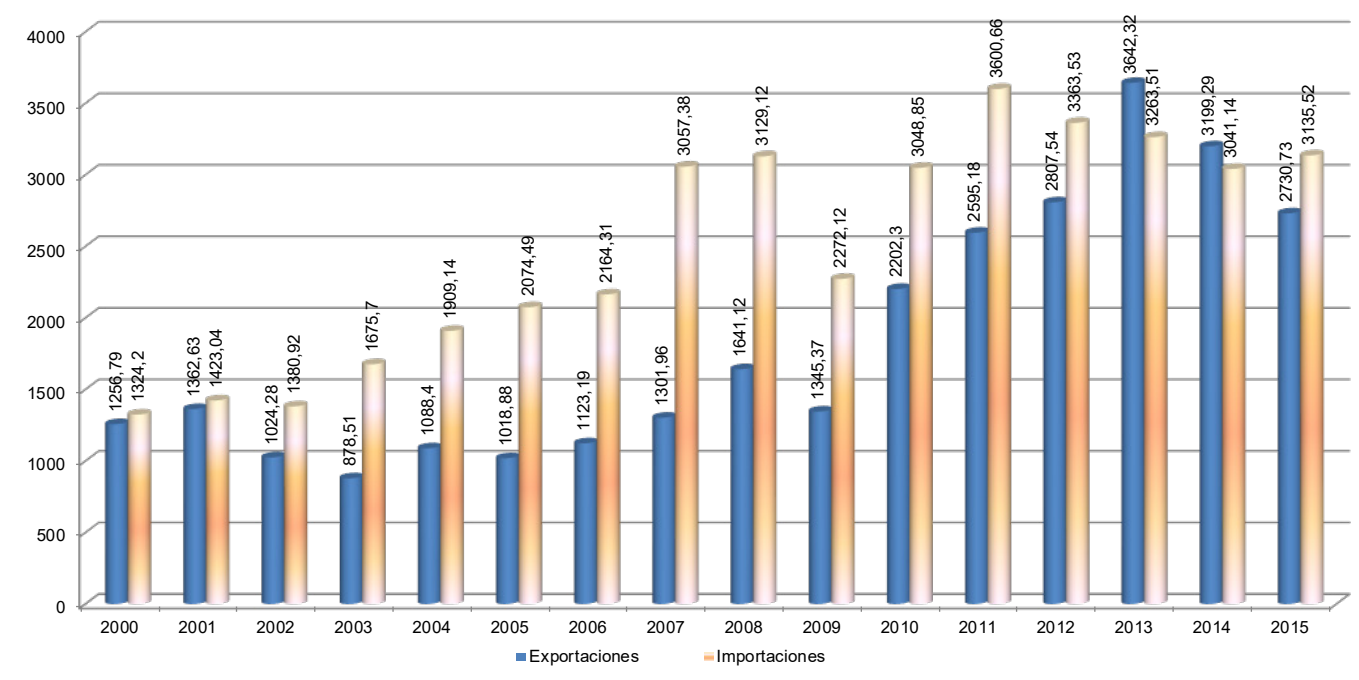

Gráfico 1. Comercio España-Brasil 2000-2015. Millones de euros.

Fuente: Datos ESTACOM. Consultado [05-09-2016]. 
En efecto, España vive una etapa de euforia y gran vitalidad del mercado interno. La llegada de la moneda única (Euro) y la estabilidad monetaria que garantiza el Banco Central Europeo abren una era de dinero barato (créditos a la inversión y el consumo, hipotecas inmobiliarias), baja inflación, bajo desempleo, intensa inmigración y consumismo sin freno mientras se incuba la tremenda burbuja inmobiliaria y financiera que hundirá al país en la crisis económica más intensa y prolongada de su historia reciente.Y en lo exterior se acentúa el intercambio con los países socios de la UE tras la entrada en vigor de la moneda común así como se incrementa el interés por mercados emergentes de Asia-Pacífico (con China como mercado prioritario); Europa del Este y África, con relajamiento que no olvido, de las relaciones con los países socios comerciales tradicionales de América Latina.

En contraste con la atonía enunciada, en los años siguientes marcados en España por la crisis económica así como la propia UE que se debate entre la atonía o el estancamiento económico y la crisis de deuda de los países del sur pone en jaque (desquicia) a las autoridades económicas, los mercados de América Latina vuelven a ser cortejados por las empresas españolas con éxito ya que las exportaciones a las mayores economías de la región como la brasileña adquieren ritmos de crecimiento claramente superiores al conjunto de los mercados internacionales. Tomado, una vez más el valor de las exportaciones en 2000 como referencia, en 2015 las ventas de España al exterior ascendieron al 201,51\%, las de América Latina-Caribe al 203,58\% y las de Brasil al 217,27\%. Los índices de crecimiento de las exportaciones en estos años de crisis resultan más expresivos tomando el valor de 2007 como base 100. Para 2015 las exportaciones a escala mundial suben al 135,24\%, hacia América Latina-Caribe alcanzan el $159,82 \%$ y a Brasil más que se doblan al situarse en el $209,73 \%$.

Distinto es el comportamiento de las importaciones de España de bienes exportados por Brasil que muestran incremento de forma bastante regular a lo largo de los años objeto de estudio, a menor ritmo hasta 2006 (valor de 163,44\% respecto a 2000) para acelerarse en los años siguientes hasta situarse en valores máximos del 271,91\% en 2011 (3.600 mills/€) abriéndose en los años siguientes una desaceleración que se torna en fuertes pérdidas en 2014 y 2015, fecha en que apenas asciende su valor al 87,1\% alcanzado en 2011.

Al igual que en los años 1990 de la anterior centuria, de 2000 a 2015 el saldo comercial bilateral será siempre negativo para España excepción hecha de los años 2013 y 2014. En 2005 y 2007 el índice de cobertura de las exportaciones de España es inferior al $50 \%$ de los desembolsos por las importaciones mientras que en 2013 se elevan al 111,61\% y en 2014 al 105,20\%. El año 2007 ostenta también el record en el monto del déficit comercial con 1.755,41 millones/€. El valor medio anual de las exportaciones a Brasil respecto de las exportaciones totales de España en el periodo ha sido del 1,01\%, nivel del que se parte en 2000 para seguir una senda descendente en los años siguientes con mínimo del 0,63\% en 2003 y tan solo en 2010 superar el nivel del año 2000 para incrementarse al 1,54\% en 2013 aunque 2015 concluye en el 1,09\% (Gráfico 2).

Respecto de las exportaciones de España a América Latina-Caribe, Brasil representa el 16,65\% en 2000 y el 17,60\% en 2001 perdiendo valor en los años siguientes hasta quedar reducido al $12,60 \%$ en 2005 y 11,42 en 2006. La progresión de su cuota en las exportaciones a la región de los años siguientes culmina en 2013 en que representa el 23,67\% de los bienes vendidos por España a la región. La crisis económica que entonces se abre en Brasil se traduce en la reducción de varios puntos en su cuota en los bienes exportados por España a América Latina-Caribe en 2014 y 2015 cuando apenas representa el $17,77 \%$. Porcentaje que le sigue garantizando su condición de segundo receptor de bienes procedentes de España en la región aunque lejos de México que supera el $27 \%$. (Gráfico 2).

El Estudio Económico de América Latina y El Caribe 2016 de CEPAL, sitúa el menor nivel de actividad interna y la depreciación de la moneda como causas de la fuerte contracción que experimentan en 2015 las ventas a Brasil desde los mercados internacionales, causas reflejadas también por el Informe Económico y Comercial sobre el país de la Oficina de España en Brasilia (Oficina Económica y Comercial, 2015, p. 46). Debe tenerse presente que la caída de los precios de las materias primas 
viene erosionando la posición internacional del país desde unos años antes ya que constituyen el capítulo mayoritario de las exportaciones de Brasil y su valor en 2014 ha caído el 13,10\% respecto de 2011 según CEPAL (2016, p. 104). La cancelación o postergación en el tiempo de grandes proyectos en infraestructuras físicas de comunicaciones (ferrocarriles, carreteras, aeropuertos) energía o infraestructura urbana (Arahuetes \& Cavalcanti, 2014, p. 219) programados por el gobierno Rousseff será una de las graves consecuencias que, lógicamente, se reflejan en la reducción de las exportaciones españolas en el último bienio e incluso la tendencia se agrava en 2016 según los datos (provisionales) de exportaciones de España al país carioca que facilita ESTACOM.

En efecto, la economía brasileña se deteriora gravemente conforme avanza 2015 ya que, si bien el retroceso del 3,9\% del PIB en el año es un mal dato, en el IV trimestre, la degradación escaló al 5,9\% en tasa interanual (Informe Trimestral de Comercio Exterior, IV trimestre, 2015) y la confirmación oficial para el año 2016 de la caída del PIB en menos 3,6\% $(-3,6 \%)$ certifica la intensidad alcanzada por la crisis que es política y social además de económica con el impeachment a la presidenta Rousseff.

\subsection{La naturaleza de los bienes exportados y sus cambios}

La cantidad medida en valor de las exportaciones es un indicador relevante para conocer el nivel de las relaciones económicas entre los países, no obstante, la naturaleza de los bienes intercambiados catalogados por sector y rama de producción por la CNAE-2009, permite evaluar su condición cualitativa en función de que su composición o naturaleza incorpore mayor o menor valor añadido, sea técnicamente más o menos sofisticada o más primaria. La clasificación por sector y rama de actividad también permite cuantificar qué sectores y ramas de actividad son dominantes, ocupan una posición secundaria, su comercio es irregular en el tiempo o sencillamente no registran exportaciones o son circunstanciales.

En un primer nivel de análisis general del periodo 2000-2015, las exportaciones de España a Brasil por valor de 29.115,15 millones de euros, presentan un grado elevado de concentración en tan solo diez ramas de actividad con un valor conjunto de negocio superior a 22.510 millones/€ y el 77,32\% del total exportado como muestra la Tabla 4. Más específicamente, las cuatro ramas que encabezan la relación así como tienen tamaño muy distinto entre ellas, cuando las sumamos, su aportación es abrumadora pues con 15.286,52 millones de euros representan más de la mitad de las ventas con el 52,00\% de las exportaciones en el periodo. No obstante, la situación general se presenta más diversa y contrastada cuando se analiza la

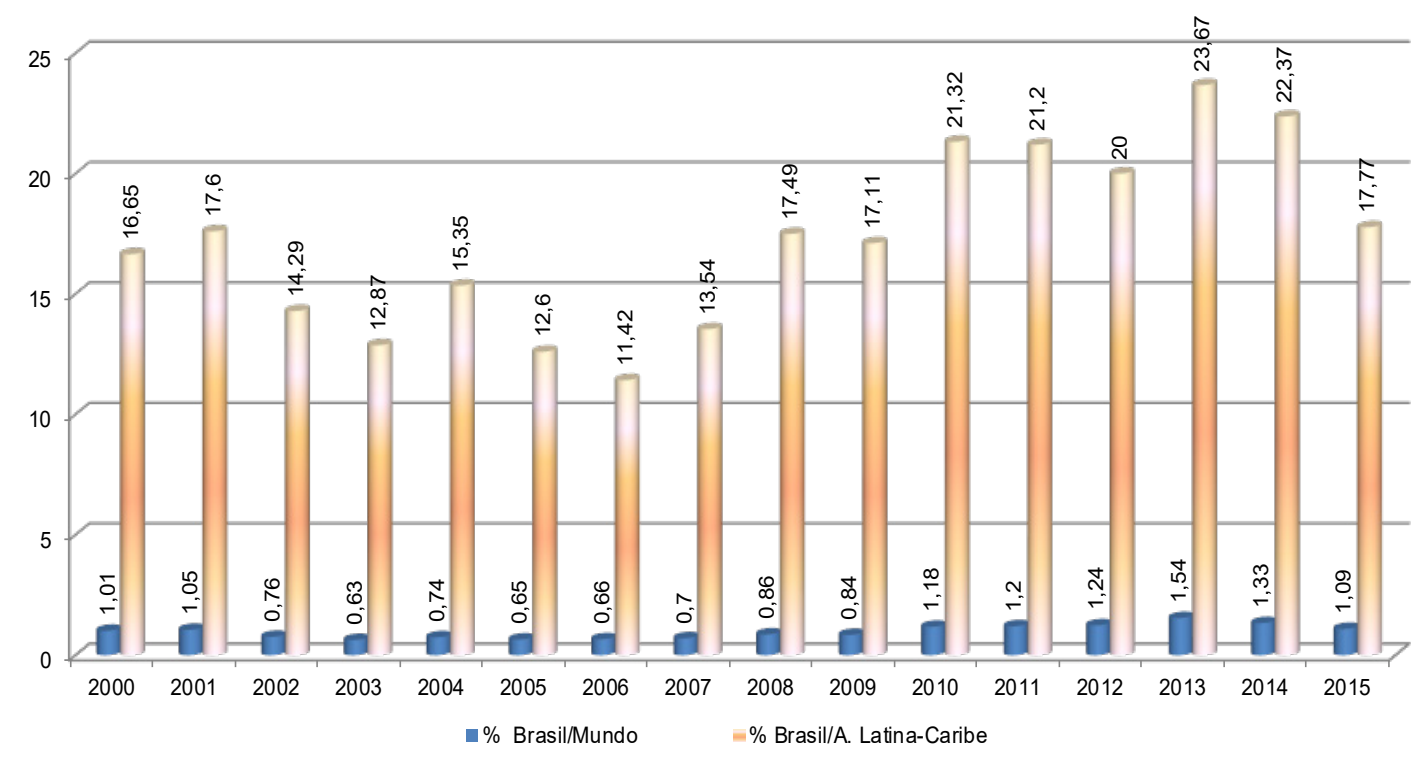

Gráfico 2. Porcentaje de las exportaciones a Brasil en el mundo y A. Latina-Caribe Fuente: Datos ESTACOM. Consultado [05-09-2016]. 
composición de las exportaciones en diferentes fechas del periodo.

En los años iniciales, en el bienio 2000-2001, la concentración de la actividad exportadora en las 10 ramas principales (Tabla 5 -A) superaba el $82 \%$ del total y respondía a la elevada concentración en las cinco ramas más grandes que en conjunto aportaban el $64 \%$ del valor exportado, entre ellas, tenía presencia destacada la rama de Fabricación de otro material de transporte $(24,10 \%)$. En esas fechas, están ya sólidamente implantadas ocho de las 10 ramas que predominan en todo el periodo 2000-2015 y ocupan posiciones más débiles las ramas Coquerías y refino de petróleo $(2,15 \%)$ y Metalurgia, fabricación de productos del hierro y el acero (1,73\%). En cambio, aparecen entre las 10 mayores la rama de Fabricación de productos

Tabla 4

\begin{tabular}{|c|c|c|}
\hline \multicolumn{3}{|c|}{$\begin{array}{l}\text { Las } 10 \text { ramas de mayor valor de las exportaciones } \\
\qquad(2000-2015) .\end{array}$} \\
\hline Rama de actividad & Millones/€ & $\%$ \\
\hline Industria química & $4.788,04$ & 16,45 \\
\hline $\begin{array}{l}\text { Fabricación de otro } \\
\text { material de transporte }\end{array}$ & $4.123,20$ & 14,16 \\
\hline $\begin{array}{l}\text { Fabricación de maquinaria } \\
\text { y equipo n.c.o.p. }\end{array}$ & $3.708,51$ & 12,74 \\
\hline $\begin{array}{l}\text { Fabricación de vehículos de } \\
\text { motor, remolques y semirremolques }\end{array}$ & $2.666,77$ & 9,16 \\
\hline $\begin{array}{l}\text { Fabricación de material y } \\
\text { equipo eléctrico }\end{array}$ & $1.610,78$ & 5,53 \\
\hline Coquerías y refino de petróleo & $1.575,56$ & 5,41 \\
\hline Industria de la alimentación & $1.123,88$ & 3,86 \\
\hline $\begin{array}{l}\text { Fabricación de productos } \\
\text { farmacéuticos }\end{array}$ & $1.044,04$ & 3,59 \\
\hline $\begin{array}{l}\text { Metalurgia; fabricación de productos } \\
\text { de hierro, acero y ferroaleaciones }\end{array}$ & $1.003,00$ & 3,44 \\
\hline $\begin{array}{l}\text { Fabricación de productos metálicos, } \\
\text { excepto maquinaria y equipo }\end{array}$ & 866,88 & 2,98 \\
\hline SUBTOTAL & $22.510,66$ & 77,32 \\
\hline Resto de las ramas & $6.604,49$ & 22,68 \\
\hline TOTAL & $29.115,15$ & 100,00 \\
\hline
\end{tabular}

Fuente: ESTACOM. Consultado [05-09-2016]. informáticos, electrónicos y ópticos (5,20\%) así como la de Fabricación de productos de caucho y plásticos (3,68\%). (Tabla 5).

Transcurridos años de notable atonía de las exportaciones hacia el mercado brasileño, en el bienio 2007-2008, el valor (2.943,09 millones/€) superaba ligeramente el de 2000-2001 (2.619,42 millones/€). La concentración de la actividad en las 10 ramas más importantes se mantiene en valores muy similares a los del bienio 2000-2001 e incluso las 5 ramas principales ganan unas décimas en el total aunque se ha producido entre ellas un claro reequilibrio de sus valores económicos (Tabla 5-B) perdiendo porcentaje Fabricación de otro material de transporte, que sigue siendo la rama de mayores ventas, a la vez que ganan peso la Industria Química, Fabricación de vehículos de motor, remolques y semirremolques y Fabricación de maquinaria y equipo n.c.o.p. Los cambios de orden por el valor de las ventas entre las principales ramas de actividad apenas incorpora cambios de rama ya que ocho de ellas se repiten en ambas fechas. Se caen del grupo las ramas de Fabricación de productos informáticos, electrónicos y ópticos (2,82\%) y la de Fabricación de productos farmacéuticos $(2,23 \%)$, reemplazadas por las de Coquerías y refino de petróleo $(4,20 \%)$ y Metalurgia, fabricación de productos del hierro, acero $(3,42 \%)$.

Calificarlo de ruptura con la naturaleza del mercado en años anteriores pudiera resultar exagerado pero el volumen de las exportaciones y su composición por sector y rama de actividad en el bienio 20142015 es muy distinta a la presentada en fechas anteriores. Sin duda, las políticas de expansión del mercado interior de Brasil de los gobiernos Lula y Rousseff y la consolidación de la llamada clase $\mathrm{C}$, por sí solos, no explican el crecimiento de las exportaciones en un contexto de contracción prolongada del mercado español a partir de 2008. En cambio, es pasible que, a la vista del crecimiento de las exportaciones españolas en años recientes, sean acertadas las frecuentes referencias de la prensa económica especializada a que son el fruto del esfuerzo de internacionalización que muchas empresas españolas han realizado a partir de 2009/2010 como estrategia, en unos casos de supervivencia pero, con frecuencia, de un salto cualitativo en su escala de mercado (las empresas exportadoras de España pasan de 109.363 en 2010 
Tabla 5

\begin{tabular}{|c|c|c|c|c|c|c|}
\hline \multicolumn{7}{|c|}{ Composición de las 10 ramas de mayor valor exportado (2000-2015). } \\
\hline & \multicolumn{2}{|c|}{ Bienio 2000/2001 (A) } & \multicolumn{2}{|c|}{ Bienio 2007/2008 (B) } & \multicolumn{2}{|c|}{ Bienio 2014-2015 (C) } \\
\hline Rama de actividad & Millones/€ & $\%$ & Millones/€ & $\%$ & Millones/€ & $\%$ \\
\hline $\begin{array}{l}06 \text { - Extracción de crudo de petróleo } \\
\text { y gas natural }\end{array}$ & - & - & - & - & 290,52 & 4,9 \\
\hline 10 - Industria de la alimentación & 87,08 & 3,32 & 112,3 & 3,82 & 273,9 & 4,62 \\
\hline 19 - Coquerías y refino de petróleo & - & - & 123,63 & 4,2 & 379,06 & 6,39 \\
\hline 20 - Industria química & 242,74 & 9,27 & 461,45 & 15,68 & $1.042,44$ & 17,58 \\
\hline $\begin{array}{l}21 \text { - Fabricación de productos } \\
\text { farmacéuticos }\end{array}$ & 73,29 & 2,80 & - & - & 300,14 & 5,06 \\
\hline $\begin{array}{l}22 \text { - Fabricación de productos de } \\
\text { caucho y plásticos }\end{array}$ & 96,48 & 3,68 & 94,14 & 3,2 & - & - \\
\hline $\begin{array}{l}24 \text { - Metalurgia; fabricación de productos } \\
\text { de hierro, acero y ferroaleaciones }\end{array}$ & - & - & 100,62 & 3,42 & 197,34 & 3,33 \\
\hline $\begin{array}{l}25 \text { - Fabricación de productos metálicos, } \\
\text { excepto maquinaria y equipo }\end{array}$ & 83,51 & 3,19 & 108,62 & 3,69 & - & - \\
\hline $\begin{array}{l}26 \text { - Fabricación de productos } \\
\text { informáticos, electrónicos y ópticos }\end{array}$ & 136,19 & 5,20 & - & - & - & - \\
\hline $\begin{array}{l}27 \text { - Fabricación de material y equipo } \\
\text { eléctrico }\end{array}$ & 207,46 & 7,92 & 99,55 & 3,38 & 398,56 & 6,72 \\
\hline $\begin{array}{l}28 \text { - Fabricación de maquinaria y equipo } \\
\text { n.c.o.p. }\end{array}$ & 349,79 & 13,35 & 413,74 & 14,06 & 712,28 & 12,01 \\
\hline $\begin{array}{l}29 \text { - Fabricación de vehículos de motor, } \\
\text { remolques y semirremolques }\end{array}$ & 244,44 & 9,33 & 374,63 & 12,73 & 378,28 & 6,38 \\
\hline $\begin{array}{l}30 \text { - Fabricación de otro material de } \\
\text { transporte }\end{array}$ & 631,23 & 24,10 & 513,32 & 17,44 & 521,43 & 8,79 \\
\hline Subtotal 5 ramas principales & $1.675,67$ & 63,97 & $1.886,78$ & 64,11 & $3.053,78$ & 51,5 \\
\hline Subtotal 10 ramas principales & $2.152,24$ & 82,16 & $2.402,00$ & 81,61 & $4.493,95$ & 75,78 \\
\hline Resto de las rasmas & 467,18 & 17,84 & 541,09 & 18,39 & 1436,08 & 24,22 \\
\hline TOTAL & $2.619,42$ & 100 & $2.943,09$ & 100 & $5.930,03$ & 100 \\
\hline
\end{tabular}

Fuente: ESTACOM. Consultado [05-09-2016]. 
a 147.731 en 2014 según ICEX, mientras a Brasil exportaban 1.214 en 2000 y en 2011 son 1.663 según Mínguez, p. 206).

La propia Tabla 5 permite comprobar los cambios en la composición y fortaleza de las diez principales ramas de exportación en el bienio 2014-2015 (sección C de la Tabla) respecto de la composición que presentaban los bienios anteriores (secciones A y B). La primera constatación es que los cambios no se deben a que en la actualidad se haya incrementado el número de ramas de actividad que realizan exportaciones a Brasil respecto de las que exportaban en 2007-2008 pues el número sigue siendo el mismo, el cambio se ha producido en el incremento del valor de las ventas por rama de actividad derivado del aumento de negocio de las empresas ya instaladas y el paulatino incremento de las mismas que de 2000 a 2011 aumentaron más del 37\% (Minguez, 2014, p. 199). Incremento de negocio y de empresas por ramas de actividad que ha reducido notablemente la concentración tanto en las 10 más importantes que aportan el 75,78\% del valor exportado como de las cinco más grandes que reducen su aportación al 51,5\% del total.

El notable incremento de las exportaciones de España desde el inicio de la crisis económica conjuga la estrategia de incrementar su negocio en el país por las empresas que venían exportando a Brasil en fechas anteriores y la incorporación de empresas ausentes en el pasado. Se trata de una convergencia de estrategias que se ha presentado como un proceso de internacionalización de numerosas empresas españolas medianas incluso pequeñas, manera de proceder que ha contribuido a que ganen peso en el valor final de lo exportado ramas de actividad cuya aportación individual es inferior al 3,33\% de todo lo exportado en el bienio.

En los años 2014-2015, la composición del grupo de las 10 ramas de producción con mayor presencia en las exportaciones mantiene la tónica de años anteriores pues, de nuevo, ocho de las ramas estaban presentes en 2007-2008 y una de las dos que se incorporan, Fabricación de productos farmacéuticos, formaba parte del grupo en 20002001. Por tanto, únicamente la rama Extracción de crudo de petróleo y gas natural, constituye una nueva incorporación al grupo de las ramas de mayor aportación al valor final de las exportaciones.
Se trata de la única rama de actividad con peso relevante que estaba ausente en fechas anteriores a 2012 y el recurso energético que protagoniza su mercado es el gas. Las ramas presentes en 20072008 que desaparecen del grupo en 2014-2015 son Fabricación de productos de caucho y plásticos $(2,67 \%)$ y Fabricación de productos metálicos, excepto maquinaria y equipo $(2,36 \%)$.

Junto a las actividades reflejadas como las de mayor valor en las exportaciones de España a Brasil existen otras ramas de actividad con sólida trayectoria de venta a este país, aunque con valores más modestos de sus exportaciones a lo largo del periodo 2000-2015. Es la situación en la que se encuentran las actividades de Agricultura, ganadería, caza y servicios relacionados $(1,88 \%)$, Confección de prendas de vestir $(1,41 \%)$, Industria del papel $(1,40)$ y Fabricación de otros productos minerales no metálicos (2,31\%). Estas ramas de actividad tienen en común niveles de ventas anuales, en general, superiores al $1 \%$ del total de cada año. Posición más precaria es la de ramas con nivel medio de exportación en el periodo 2000-2015 inferior al 1\% pero que lo superan en momentos concretos. Son las ramas Industria textil (1,06\% en 2000-2001 y 2007-2008); Otras industrias manufactureras $(1,11 \%$ en $2000-2001)$ y la rama Edición, con ventas próximas al 2\% en 2000-2001 y 2007-2008.

Finalmente, cabe identificar la composición de los bienes concretos que, en la actualidad, lideran las exportaciones a Brasil, cuáles son los productos que encabezan el ranking entre los bienes españoles presentes en el mercado brasileño. En 2014-2015, en la Industria Química, la principal rama con el $17,6 \%$, destacan los productos químicos básicos, los compuestos nitrogenados, fertilizantes, caucho y plásticos en formas primarias (70,5\% del total), cubriendo el resto los epígrafes detergentes y artículos de limpieza, pesticidas y agroquímicos, pinturas y barnices. Se trata de una gama de productos con sólida presencia en Brasil, algunos de ellos incluso antes del 2000.

Los Bienes de equipo y maquinaria en general (motores, turbinas, bombas y compresores, etc.) así como Material eléctrico (motores, generadores, transformadores eléctricos), tienen presencia destacada ganando peso en el total de las 
exportaciones con el paso de los años al igual que Otro material de transporte, definido por la construcción de locomotoras, equipamiento ferroviario, aeronáutico y espacial. A su vez, la rama de Fabricación de vehículos de motor, remolques..., ha perdido protagonismo en los últimos lustros (coches, carrocerías, componentes, piezas y accesorios del vehículo) respecto al adquirido hacia 2000 (Espíndola \& Marthins, 2017, p. 170).

Respecto de la La Industria Alimentaria, que es un sector potente en las exportaciones totales de España, sigue lejos del potencial que ofrece el mercado brasileño pero es muy cierto que ha de vencer pautas de consumo locales muy arraigadas de modo que su progresión debe entenderse lenta. Los procesados de carne, pescado o verduras tienen presencia discreta mientras los aceites vegetales ganan protagonismo así como los vinos.

Por su parte, las actividades vinculadas a los servicios mantienen un perfil muy bajo si bien el turismo ha experimentado un notable incremento y en el ámbito cultural, del conocimiento y la creación, la Edición tiene una sólida presencia favorecida por la implantación en el país de editoriales españolas (Planeta, editorial SM, ediciones Del Prado SA).

Ordenadas las exportaciones totales de España y las dirigidas a Brasil durante bienio 2014-2015, por la afinidad de su naturaleza en los 9 sectores que la propia base de datos ESTACOM ofrece (Tabla 6), se ponen de manifiesto algunos rasgos dominantes de diferenciación entre ambos mercados. La obviedad primera es que los mimbres sobre los que se asientan los pretendidos objetivos de finales de los años 90 para forjar unas sólidas bases de impulso futuro de los intercambios comerciales parecen no haberse cumplido a satisfacción y Brasil únicamente absorbe el 1,2\% de las exportaciones del bienio resultado de ser el socio comercial 16/17 en esos años por volumen de compras a España. (Tabla 6).

En segundo lugar, la distribución por sectores de las exportaciones está más abierta o distribuida en las del resto del mundo que en las de Brasil. Aunque sí hay coincidencia en los sectores de semifacturas y bienes de equipo, en Brasil la concentración en ambos es mucho más alta $(65,2 \%)$ que en el resto
(45,0\%). Pecisamente, algunos de los autores citados al estudiar las relaciones comerciales bilaterales al filo del cambio de siglo, señalaban la diversificación como una de las prioridades de las medidas a tomar en adelante. Cierto que en años recientes ha emergido el sector de las energías (derivados de petróleo/petroquímica y gas) como uno de los más dinámicos, mientras no lo es en las exportaciones generales ya que España carece de la materia prima de hidrocarburos. Los otros dos sectores de mayor dimensión en las exportaciones generales, el sector del automóvil sigue trayectoria declinante en Brasil mientras los productos alimentarios ya hemos indicado que encuentran serias dificultades para asentarse en el mercado brasileño.

\subsection{El origen de las exportaciones por CC. AA.}

La geografía de la internacionalización de la economía a través del comercio y las inversiones de capital así como su dimensión territorial en las comunidades autónomas (CC. AA.) y provincias, son ámbitos espaciales de análisis que, hasta el presente, han recibido escasa atención y estudio por parte de la comunidad de geógrafos españoles. La distribución por CC. AA. de las exportaciones a Brasil remiten al predominio de las comunidades con especialización productiva industrial más marcada, así como el tamaño de su economía ha de ser valorado. No obstante, la primera evidencia de la evolución de las exportaciones por CC. AA. es que en el bienio 2014-2015 respecto del valor de los bienes exportados en 2007-2008, todas las regiones, excepción hecha de Cantabria, incrementaron su valor, en ocasiones, de manera notable.

A lo largo del periodo de estudio, Cataluña es el territorio que tiene un protagonismo más destacado' seguida de la otra mayor economía industrial del país, el País Vasco. Menor peso de su base productiva industrial junto al tamaño, dan a Madrid la tercera posición seguida de Andalucía y Comunidad Valenciana (Gráfico 3). En conjunto, el $72,67 \%$ de las exportaciones hacia Brasil de 2000 a 2015 , tienen su origen en estas cinco comunidades autónomas.

No siendo objetivo del texto adentrarse en el estudio detallado del origen geográfico de las exportaciones, queda fuera del mismo analizar la estructura productiva, el tamaño o el grado 
Tabla 6

\begin{tabular}{|l|c|c|c|c|}
\hline \multicolumn{5}{|c|}{$\begin{array}{c}\text { Tabla 6. España: exportaciones totales y a Brasil por sectores económicos } \\
\text { (Bienio 2014-2015). }\end{array}$} \\
\hline & \multicolumn{2}{|c|}{ España } & \multicolumn{2}{c|}{ Brasil } \\
\hline Sectores & Millones/€ & $\%$ & Millones/€ & $\%$ \\
\hline 1. Alimentos & $77.944,2$ & 15,9 & 465,1 & 7,8 \\
\hline 2. Productos energéticos & 30.272 & 6,2 & 669,8 & 11,3 \\
\hline 3. Materias primas & $11.300,1$ & 2,3 & 70,6 & 1,2 \\
\hline 4. Semimanufacturas & $121.989,1$ & 24,9 & $1.925,7$ & 32,5 \\
\hline 5. Bienes de equipo & $98.446,3$ & 20,1 & $1.939,9$ & 32,7 \\
\hline 6. Sector del automóvil & $78.287,4$ & 16,0 & 367,3 & 6,2 \\
\hline 7. Bienes de consumo duradero & $7.387,9$ & 1,5 & 36,7 & 0,6 \\
\hline 8. Manufacturas de consumo & $45.809,6$ & 9,3 & 264,2 & 4,5 \\
\hline 9. Otras mercancías & $18.939,5$ & 3,9 & 188,5 & 3,2 \\
\hline TOTAL & $490.376,2$ & 100,0 & $5.928,1$ & 100,0 \\
\hline
\end{tabular}

Fuente: ESTACOM. Consultado [05-08-2016].

de especialización productiva de los territorios donde se originan las mercaderías exportadas a Brasil. No obstante, del análisis general de los datos facilitados por la base estadística ESTACOM para las distintas comunidades autónomas durante los años del periodo de estudio se pueda avanzar una breve valoración matizada su dinámica temporal para los bienios 2000-2001, 2007-2008 y 2014-2015, ya que, en efecto, se registran oscilaciones relevantes tanto a nivel de CC. AA. como entre comunidades de unas fechas a otras.

A título de ejemplo, Andalucía pasó de representar

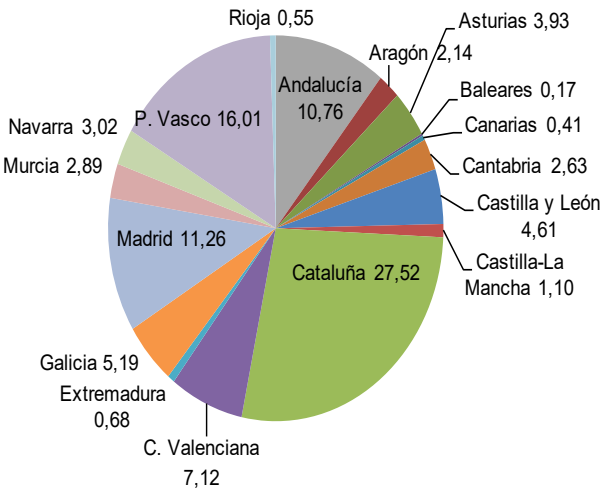

Gráfico 3. Exportaciones \% de las comunidades autónomas 2000-2015. Fuente: Datos ESTACOM. apenas el 6,3\% de las exportaciones en 2000-2001, al 15,2\% en el bienio 2007-2008 para retroceder en 2014-2015 al 9,4\%. Por su parte, Cataluña en 20002001 aportó más del 32\% de las exportaciones, descendiendo al $26,9 \%$ en $2007-2008$ y al $25,1 \%$ en 2014-2015. El País Vasco aporta el $18,6 \%$ en 2000-2001 sube al 21,4\% en 2007-2008 y retrocede al $12,3 \%$ en $2014-2015$. La comunidad de Madrid presenta una trayectoria irregular en la medida en que en 2000-2001 aporta el 12,2\%, retrocede al $8,1 \%$ en 2007-2008 para remontar hasta el $14,8 \%$ en 2014-2015. A su vez, la Comunidad Foral Navarra incrementa su cuota desde el débil 1,9\% en 2000-2001 al 2,4\% en 2007-2008 y al 5,0\% en el último bienio. No obstante, el crecimiento más espectacular de la cuota de exportación corresponde a la región de Murcia que del 0,9\% en 2007-2008, inicio de la crisis económica, sube al 5,4\% en 2014-2015.

Por su parte, regiones como Aragón, Asturias o Castilla y León, con baja presencia inicialmente, con el paso de los años incrementan su potencial exportador hasta niveles bastante similares a su peso en la economía del país mientras regiones como Galicia (2,6\% en 2014-2015) o La Rioja (0,3\% en 2014-2015) permanecen en niveles inferiores al de su PIB en el conjunto nacional. 


\section{Potencialidades abiertas, estrategias a implementar}

La naturaleza y el valor del comercio bilateral entre España y Brasil en el tiempo transcurrido de la centuria actual debe contextualizarse a la luz de la regulación del Acuerdo Marco de Cooperación UE/MERCOSUR, espacios ambos de cooperación e integración económica en los que se insertan los dos países y que desde el año 2007 incorporan una Asociación Estratégica entre ambas esferas económicas. Si bien las dificultades, en ocasiones más de carácter político que comercial, han impedido que se cerrara el acuerdo que permita culminar la ampliación y profundización de los regímenes comerciales vigentes que siguen entrañando limitaciones importantes a los intercambios comerciales en numerosas áreas de actividad, en el momento actual, tras los cambios políticos que se han dado en Argentina y la deriva proteccionista pregonada por la administración USA, la UE y MERCOSUR parecen dispuestos a cerrar un acuerdo que potencie su vocación de espacios económicos abiertos al libre comercio. Por lo que el cierre de las conversaciones de forma positiva debe redundar en el incremento del potencial de intercambio comercial entre los países miembros de una y otra comunidad de integración económica. El monto de los intercambios comerciales entre ambos espacios económicos son ya en la actualidad de gran importancia para los países de MERCOSUR pues ascienden al $21 \%$ de su comercio exterior.

Pero si los nuevos acuerdos de liberalización de los intercambios deben propiciar el incremento futuro del comercio bilateral, la trayectoria de las exportaciones de España a Brasil reclama reflexión y quizás reorientación de las prácticas comerciales seguidas en fechas anteriores. El mayor mercado de América Latina que es Brasil sigue a la zaga de las exportaciones españolas en el mercado mexicano por lo que, dada la diferencia de tamaño de ambos y la afinidad cultural con los dos países, España debe identificar con precisión cuáles son las razones por las que siendo Brasil un socio privilegiado desde finales de los años 1990 del siglo pasado para sus capitales sigue sin serlo para sus bienes comerciales. En primer lugar y de forma general, no se puede obviar que, más allá de la coyuntura actual con severas limitaciones en el comercio exterior derivadas de la crisis económica, social y política que aqueja a Brasil y que en clave social interna puede justificar el sesgo proteccionista, el país sigue proyectándose como un mercado aún bastante cerrado al comercio internacional de modo que su índice ${ }^{2}$ de apertura comercial en 2014 apenas alcanza el $25 \%$ mientras que supera el $48 \%$ en España.

En segundo lugar, Hay que asumir el hecho de que además de la eliminación de barreras arancelarias se han de incorporar "acordos para a transferência tecnológica, capacitação de mão de obra, joint ventures, etc., para que os desequilibrios atuais sejam derimidos" (Espíndola \& Marthins, 2017, p. 173). Criterio que redunda en la necesidad que España, en particular, tiene de implementar medidas orientadas tanto a conocer mejor los potenciales nichos de mercado que Brasil presenta como a incorporar medidas concretas para diversificar más la naturaleza de sus ventas y que éstas incorporen contenidos tecnológicos y de conocimiento más complejos y aporten mayor valor añadido. La pervivencia en la actualidad del fuerte protagonismo de dos únicos sectores de actividad denuncia las carencias a superar.

En tercer lugar, la experiencia de la crisis económica por la que ha pasado España en los últimos años y el papel balsámico que el sector exterior ha desempeñado ha fraguando una amplia y sólida confianza en la profundización de la internacionalización de las empresas y de apertura a la competencia exterior del mercado local. Cultura que debe inducir en empresas y en la propia administración prácticas y programas orientados a profundizar las relaciones comerciales en general y con Brasil en particular.

No obstante, de prolongarse en el tiempo el retraimiento del mercado brasileño a las mercancías españolas, se cierne sobre los intercambios bilaterales el riesgo de reorientación geográfica de parte de las exportaciones que en fechas anteriores se dirigían al mercado brasileño como medida no tanto de renuncia a este mercado sino como alternativa temporal o, tal vez, definitiva para la venta de los bienes que la crisis económica ha expulsado del mercado brasileño. 


\section{NOTAS}

En 2011 el valor de sus exportaciones ascendieron al 25,73\% de las de España pero la participación de sus empresas llegaba al 43,8\% "proporción prácticamente inalterada durante la última década" según Mínguez (2014, p. 205)

${ }^{2}$ Indicador que mide la proporción del comercio exterior -la suma de exportaciones e importaciones- sobre el producto interior bruto (PIB) del país.

\section{FUENTES}

Base de datos ESTACOM. Recuperado de [http://www.icex. es/icex/es/estadisticas-espanolas-estacom/index.html]. Consultado [05-10-2016].

\section{REFERENCIAS BIBLIOGRÁFICAS}

Alonso, J. L., Mendes, A. \& Guarnieri, S.A. (2017). La inversión exterior directa de España en Brasil 1996-2015. Revista de Estudios Brasileños, 4(6), 176-190.

Arahuetes, A. \& Hiratuka, C. (2007). Relaciones económicas entre España y Brasil. Madrid: Real Instituto Elcano.

Arahuetes, A., Gomes, J. S. \& Moreira, A. (2010). La internacionalización de la empresa española. Estudio monográfico sobre el entorno económico y las oportunidades de inversión en Brasil. ICEX-ICO. Fundación Real Instituto Elcano.

Arahuetes, A. \& Cavalcanti, M. (2014). Oportunidades de comercio, infraestructuras e inversiones directas para las empresas españolas en Brasil. Brasil un gran mercado en expansión sostenida ( $2^{\mathrm{a}}$ ed.). Santander: Cátedra Nebrija Santander, Universidad Antonio de Nebrija.

Audera, V. (2003). Relaciones económicas y comerciales con Brasil. Información Comercial Española (ICE), 810, oct.-nov. 2003, 47-69.

Ayllón, B. (2007). Las relaciones hispano-brasileñas: de la mutua irrelevancia a la asociación estratégica (1945-2005). Salamanca: Ediciones Universidad de Salamanca.

Banco Mundial (BM). Perspectivas económicas mundiales. Recuperado de [http://www.bancomundial.org]. Consultado [27-07-2017].

CIDOB. (2004). Brasil, perfil de país. Anuario Internacional 2003, 561-572. Recuperado de [https://www.cidob. org/es/publicaciones/serie_de_publicacion/anuario_ internacional_cidob/anuario_internacional_cidob_2003 edicion_2004_brasil_perfil_de_pais]. Consultado [20-062017].

Comisión Económica para América Latina y el (CEPAL) (2015). Informe Estadístico de la Economía brasileña, oct.dic. 2015. Recuperado de [http://repositorio.cepal.org/ handle/11362/40217]. Consultado [25-06-2017].

Comisión Económica para América Latina y el Caribe (CEPAL). (2016). Panorama de la inserción Internacional de América Latina y el Caribe 2015 Y 2016. Recuperado de [https://www. cepal.org/es/publicaciones/40744-panorama-la-insercioninternacional-america-latina-caribe-2016-la-region-frente]. Consultado [27-07-2017]

Comisión Económica para América Latina y el Caribe (CEPAL). (2017). Anuario Estadístico (varios años). Recuperado de [http://www.cepal.org/en/publications/]. Consultado [2407-2017].

Comisión Económica para América Latina y el Caribe (CEPAL). (2016). Estudio económico de América Latina y el Caribe 2016: Brasil. Recuperado de [https://www.cepal.org/es/ publicaciones/40326-estudio-economico-america-latinacaribe-2016-la-agenda-2030-desarrollo]. Consultado [20-072017].

Da Motta, P. (2003). Brasil: retos de la política industrial y comercial de principios del siglo XXI. Información Comercial 
Española (ICE), 810, oct.-nov. 2003, 127-136.

Espíndola, C.J. (2014). Desempenho exportador brasileiro e o transporte de cargas nos portos e terminais de uso privato. Cadernos Geográficos, 32, 6-67.

Espíndola, C. J. \& Marthins, A. (2017). Breves considerações sobre as relações comerciais Brasil e Espanha. Revista de Estudios Brasileños, 4(6), 161-175.

Expansión - Diario Económico e información de mercados. (2016). Economía y datos de los países. Recuperado de [www. datosmacro.com]. Consultado [24-10-2016].

Furlán, L. F. (2003). La alianza hispano-brasileña para un nuevo modelo de crecimiento económico. Información Comercial Española (ICE), 810, oct-nov 2003, 5-17.

García Rubio, A. R. (2014). Las relaciones comerciales entre España y Brasil: oportunidades de exportación para las empresas españolas. Brasil un gran mercado en expansión sostenida. ( $2^{\mathrm{a}}$ ed.). Santander: Cátedra Nebrija Santander, Universidad Antonio de Nebrija.

España Exportación e inversiones (ICEX). (2015). España exportación e inversiones. Análisis del comercio exterior español. Recuperado de [http://informesestadisticos. icex.es/InformesComerciales/parametros_multiselect. jsp?Tipolnforme=2 ]. Consultado [20/8/2016].

Información Comercial Española (ICE). (2015). El sector exterior en 2014. Boletín Económico, 3.065. Recuperado de [http://www.revistasice.com/es-ES/BICE/Paginas/Todos-losBoletines.aspx]. Consultado [20-07-2017].

Instituto Brasileiro de Geografia e Estatística (IBGE). (2017) Indicadores de evolución del PIB e inflación. Recuperado de [http://www.ibge.gov.br/espanhol/]. Consultado [25-072017].

Instituto Nacional de Estadística (INE). Datos Estadísticos. Recuperado de [http://www.ine.es/]. Consultado [24-072017].

Mínguez, R. (2014). Las relaciones comerciales de las empresas españolas con Brasil. Brasil un gran mercado en expansión sostenida. ( $2^{\mathrm{a}}$ ed.) Santander: Cátedra Nebrija Santander, Universidad Antonio de Nebrija.

Oficina Económica y Comercial de la Embajada de España en Brasilia. (2015). Brasil, informe económico y comercial. Recuperado de [https://www.icex.es/icex/es/navegacionprincipal/todos-nuestros-servicios/informacion-demercados/paises/navegacion-principal/el-mercado/ estudios-informes/DOC2015601161.html?idPais=BR]. Consultado [25-07-2017].

Quirós, J. (2003). La política comercial brasileña. Información Comercial Española (ICE), 810, oct-nov 2003, 41-45.

Reyero García, J. M. (2003). La promoción comercial en Brasil y su repercusión en la imagen de España. Información Comercial Española (ICE), 810, oct-nov 2003, 35-40.

Secretaría de Estado de Comercio. Ministerio de Economía y Competitividad de España. (2016). Informe Trimestral de
Comercio Exterior. Cuarto trimestre de 2015. Recuperado de [http://www.comercio.gob.es/es-ES/comercio-exterior/ estadisticas-informes/PDF/estadisticas-comercio-exterior/ INFORME\%20TRIMESTRAL\%20IV\%20TRIMESTRE\%202015. PDF]. Consultado [30-07-2017].

Velarde, J. (1999). Interrogantes españoles ante el futuro iberoamericano. Economía Exterior, 9, 49-57.

Utrera, F. (2003). Brasil un socio estratégico de España. Información Comercial Española (ICE), 810, oct-nov 2003, 19-22. 